\title{
PENGARUH PERSEPSI HARGA, CITRA MEREK DAN KUALITAS PELAYANAN TERHADAP MINAT BELI ULANG JASA GOFOOD DI KOTA SORONG
}

\author{
Retno Dewi Wijiastuti ${ }^{1}$, Nidya Cantika ${ }^{2}$ \\ ${ }^{1}$ Fakultas Ekonomi Universitas Muhammadiyah Sorong \\ Email : retnodewi@um-sorong.ac.id
}

\begin{abstract}
This study aims to determine the effect of Price Perception, Brand Image and Service Quality on GoFood Service Repurchase Interests in Sorong City (Case Study of Gojek Application Users on GoFood Services). This research was conducted in Sorong City with the respondents in this study, namely the Sorong City Community who used the Gojek Application on GoFood Services as many as 86 people. The results of the analysis show that price perceptions have a positive and significant effect on the intention to repurchase GoFood services in Sorong City, this is evidenced by the value of t count $>t$ table $(6.113>1.989)$ and a significant level of less than 0.05 (0.000 < 0.05). Brand image has an influence on the intention to repurchase GoFood services in Sorong City, this is evidenced by the value of $t$ count $>t$ table $(6,495>1,989)$ and a significant level of less than $0.05(0,000<0.05)$. on the interest in repurchasing GoFood services in Sorong City, this is evidenced by the value of $t$ count $>t$ table $(8.503>1.989)$ and a significant level of less than $0.05(0.000<0.05)$. So it can be concluded that GoFood consumer repurchase interest in Sorong is very significant
\end{abstract}

Keywords: Price Perception, Brand Image, Service Quality, Repurchase Interests

ABSTRAK : Penelitian ini bertujuan untuk mengetahui pengaruh Persepsi Harga, Citra Merek dan Kualitas Pelayanan terhadap Minat Beli Ulang Jasa GoFood di Kota Sorong (Studi Kasus Pengguna Aplikasi Gojek pada Layanan GoFood). Penelitian ini dilakukan di Kota Sorong dengan responden dalam penelitian ini yaitu Masyarakat Kota Sorong yang menggunakan Aplikasi Gojek pada Layanan GoFood sebanyak 86 orang. Hasil analisa menunjukkan bahwa persepsi harga mempunyai pengaruh positif dan signifikan terhadap minat beli ulang jasa GoFood di Kota Sorong, hal ini dibuktikan dengan nilai t hitung $>t$ tabel $(6.113>1.989)$ dan taraf signifikan kurang dari $0,05(0,000<0,05$. Citra merek mempunyai pengaruh terhadap minat beli ulang jasa GoFood di Kota Sorong, hal ini dibuktikan dengan nilai t hitung $>\mathrm{t}$ tabel $(6.495>1.989)$ dan taraf signifikan kurang dari $0,05(0,000<0,05)$. Kualitas pelayanan mempunyai pengaruh terhadap minat beli ulang jasa GoFood di Kota Sorong, hal ini dibuktikan dengan nilai $\mathrm{t}$ hitung $>\mathrm{t}$ tabel $(8.503>1.989)$ dan taraf signifikan kurang dari $0,05(0,000<$ 0,05). Sehingga dapat disimpulkan bahwa minat beli ulang konsumen GoFood di Kota Sorong sangat signifikan.

Kata kunci : Persepsi Harga, Citra Merek, Kualitas Pelayanan, Minat Beli Ulang 


\section{PENDAHULUAN}

Transportasi menjadi salah satu faktor penunjang dalam melakukan kegiatan sehari-hari terutama di daerah perkotaan, saat ini sarana transportasi dan komunikasi semakin mudah sehingga membuat aktivitas manusia menjadi lebih efisien dan praktis. Salah satu jasa layanan transportasi adalah Gojek. Munculnya Gojek di Papua Barat khususnya di Kota Sorong membuat aktivitas masyarakat menjadi lebih mudah. Gojek terus berkembang dengan meluncurkan inovasiinovasi baru dengan produk layanan jasa yang beragam. Hingga saat ini sudah ada enam belas layanan jasa yang dapat dipesan melalui aplikasi Gojek, diantaranya : GoRide, Go-Car, Go-Food, Go-Mart, GoSend, Go-Box, Go-Massage, Go-Clean, Go-Bills, Go-Pulsa, Go-Pay, Go-Point dan lain-lain. Selain itu Aplikasi GoJek juga dilengkapi dengan fasilitas Go-Pay, GoBills, Go-Point, dan Go-Pulsa.

GoFood adalah layanan pesan antar makanan yang dapat dipesan melalui aplikasi Gojek yang telah diunduh pada gadget. Konsumen dapat memesan makanan yang diinginkan melalui aplikasi, kemudian driver Gojek akan mengantarkannya ke tempat anda. Layanan ini tentu saja sangat memudahkan anda untuk memesan makanan tanpa antri dan praktis. Saat ini sudah banyak tempat makanan, minuman maupun camilan di Kota Sorong yang mendaftarkan usahanya pada layanan GoFood, sehingga konsumen memiliki pilihan makanan dan minuman yang lebih bervariasi. Di dalam aplikasi GoFood sendiri sudah tersedia informasi lengkap mengenai jenis makanan atau minuman apa saja, harga, lokasi, jarak tempuh, estimasi waktu pengantaran dan konsumen juga dapat melakukan percakapan dengan driver gojek untuk menanyakan atau menambahkan informasi tertentu.

Di Kota Sorong sendiri terdapat penyedia jasa layanan pemesanan makanan secara online seperti Gojek (GoFood), Grab (Grabfood) dan beberapa jasa layanan online lokal lainnya. Semakin banyaknya penyedia jasa layanan pemesanan makanan online tentu saja akan berdampak pada semakin ketatnya persaingan. Banyak faktor yang menjadi penyebab terjadinya hal tersebut diantaranya yaitu persaingan harga, pelayanan dan banyaknya alternatif pilihan jasa online. Konsumen tentu saja akan memilih salah satu alternative jasa layanan online yang dirasa mampu memenuhi keinginannya, oleh karena itu perusahaan jasa GoFood harus bisa menciptakan kualitas layanan, image positif dan harga yang sesuai agar dapat 
Revised : June, 22, 2021

Available online : June, 23, 2021

menciptakan kepuasan pelanggan dan

minat konsumen untuk terus menggunakan jasa layanan GoFood.

Faktor-faktor yang dianggap mampu mempengaruhi minat beli ulang konsumen diantaranya adalah harga, citra merek dan kualitas pelayanan (Hakim, 2021). Dalam penelitian Soelistio (2016) diketahui bahwa persepsi harga, promosi dan kualitas pelayanan memiliki pengaruh yang signifikan terhadap minat pembelian ulang, sedangkan dalam penelitian yang dilakukan oleh Mendrika, n.d.) (2017) diketahui bahwa brand image (citra merek) memiliki pengaruh pada minat beli ulang. Oleh karena itu tujuan penelitian ini adalah untuk mengetahui pengaruh persepsi harga, citra merek dan kualitas pelayanan terhadap minat beli ulang jasa GoFood.

\section{METODE PENELITIAN}

\section{Desain Penelitian}

Penelitian ini menggunakan metode kuantitatif dengan pendekatan deskriptif dan korelasi mengenai sikap masyarakat yang menggunakan jasa layanan GoFood.

\section{Populasi dan sampel}

Populasi dalam penelitian ini adalah seluruh pelanggan pengguna Aplikasi Gojek pada Layanan GoFood di Kota Sorong. Jumlah populasi dalam penelitian ini adalah 110 orang.
Sedangkan teknik yang digunakan dalam pengambilan sampel dalam penelitian ini yaitu teknik Purposive Sampling yaitu teknik penentuan sampel dengan pertimbangan tertentu. Sampel dalam penelitian ini berjumlah 86 orang menggunakan Rumus Slovin dengan tingkat kesalahan 5\%.

\section{Definisi Operasional}

Variabel Independen (Variabel Bebas) Independen yang digunakan adalah Persepsi Harga (X1), Citra Merek (X2) dan Kualitas Pelayanan (X3).

Indikator Variable Persepsi Harga (X1) adalah :

- Keterjangkauan Harga

- Kesesuaian Harga dengan Kualitas

- Daya Saing Harga

- Kesesuaian Harga dengan Manfaat Indikator Variabel Citra Merek (X2) adalah :

- Citra Korporat

- Citra produk/ konsumen

- Citra Pemakai

Indikator variable Kualitas Pelayanan (X3) adalah :

- Reliabitlity (keandalan)

- Responsiveness (ketanggapan)

- Assurance (jaminan)

- Tangibles (bukti langsung) 
Revised : June, 22, 2021

Available online : June, 23, 2021

Variabel Dependen yang digunakan

adalah Minat Beli Ulang (Y). Indokator

Variabel minat beli ulang :

- Keterjangkauan Harga

- Kesesuaian Harga dengan Kualitas

- Daya Saing Harga

- Kesesuaian Harga dengan Manfaat

\section{Teknik Pengumpulan Data}

1. Teknik Wawancara

Wawancara merupakan pertemuan dua orang untuk bertukar informasi dan ide melalui tanya jawab, sehingga dapat dikontruksikan makna dalam suatu tertentu.

2. Teknik Dokumentasi

Dokumentasi merupakan catatan peristiwa yang sudah berlalu. Dokumen bisa berbentuk tulisan, gambar, atau karyakarya monumental seseorang.

3. Kuisioner

Kuesioner atau angket merupakan teknik pengumpulan data yang dilakukan dengan cara memberi seperangkat pertanyaan atau pernyataan tertulis kepada responden untuk dijawab.

Pengukuran jawaban dari kuisioner yang dilakukan menggunakan pengukuran skala likert. Kuisioner yang digunakan dalam penelitian ini menggunakan 5 point skala dengan skor yang dapat diberikan sebagai berikut :

Sangat Setuju (SS)
Setuju (S) $: 4$

Netral (N) $: 3$

Tidak Setuju (TS) $: 2$

Sangat Tidak Setuju $: 1$

\section{Teknik Analisis Data}

Metode analisis data menggunakan pengujian asumsi klasik, uji normalitas, uji linieritas, uji multikolonieritas, dan Uji heteroskedatisitas. Kemudian digunakan analisa statistik yaitu regresi berganda, dengan menggunakan program aplikasi SPSS.

Adapun persamaan regresi linear berganda sebagai berikut :

Rumus: $y=\alpha+\beta_{1} x_{1}+\beta_{2} x_{2}+\beta_{3} x_{3}+e$

Keterangan :

Y : Variabel terikat (Minat Beli Ulang)

$\alpha \quad$ : Bilangan Konstanta

$\beta \quad$ : Koefisien estimate

$\mathrm{X} 1, \mathrm{X} 2, \mathrm{X} 3$ : Variabel Bebas (Persepsi Harga, Citra Merek, Kualitas Pelayanan)

e : error

HASIL DAN PEMBAHASAN

Karakteristik Responden Berdasarkan Jenis Kelamin

Tabel 1. Jenis Kelamin Responden

\begin{tabular}{cccc}
\hline No. & $\begin{array}{c}\text { Jenis } \\
\text { Kelamin }\end{array}$ & Jumlah & $\%$ \\
\hline 1. & Laki-laki & 24 & $28 \%$ \\
2. & Perempuan & 62 & $72 \%$ \\
Total & 86 & $100 \%$ \\
\hline \multicolumn{2}{l}{ Sumber : Data primer yang diolah }
\end{tabular}

Doi : https://doi.org/10.52655/khg.v1i1.3 
Revised : June, 22, 2021

Available online : June, 23, 2021

Berdasarkan tabel 1 dapat diketahui bahwa pengguna jasa GoFood lebih banyak berjenis kelamin perempuan yaitu sebanyak 62 orang atau $72 \%$, sedangkan sisanya 24 orang atau $28 \%$ adalah pengguna jasa GoFood berjenis kelamin laki- laki.

\section{Karakteristik Responden berdasarkan Usia}

Tabel 2. Usia Responden

\begin{tabular}{|c|c|c|c|}
\hline No. & Usia & Jumlah & $\%$ \\
\hline 1. & $\begin{array}{l}17-25 \\
\text { Tahum }\end{array}$ & 28 & $33 \%$ \\
\hline 2. & $\begin{array}{l}26-35 \\
\text { Tahun }\end{array}$ & 58 & $67 \%$ \\
\hline \multicolumn{2}{|c|}{ Total } & 86 & $100 \%$ \\
\hline
\end{tabular}

Sumber : Data Primer yang diolah

Berdasarkan table 2 dapat diketahui bahwa responden berusia 26 - 35 tahun merupakan responden yang paling banyak menggunakan jasa layanan GoFood sebesar 58 orang atau $67 \%$. Hal ini menunjukkan bahwa golongan milenial lebih menyukai kepraktisan dan kemudahan.

Karakteristik Responden Berdasarkan Metode Pembayaran

Table 3. Metode Pembayaran Responden

\begin{tabular}{clcc}
\hline No. & $\begin{array}{c}\text { Metode } \\
\text { Pembayaran }\end{array}$ & Jumlah & $\%$ \\
\hline $1 . \quad \begin{array}{l}\text { Non Tunai } \\
\text { (Gopay) }\end{array}$ & 62 & $72 \%$ \\
2. Tunai & 24 & $28 \%$ \\
Total & 86 & $100 \%$
\end{tabular}

Sumber : Data primer yang diolah
Berdasarkan table 3 dapat diketahui bahwa pengguna jasa layanan GoFood lebih memilih melakukan pembayaran secara non tunai melalui Gopay, hal ini sesuai dengan jawaban responden sebanyak 62 orang atau $72 \%$.

\section{Karakteristik Responden Berdasarkan Frekuensi Order}

Table 4. karakteristik Frekuensi Order Responden

\begin{tabular}{lccc}
\hline No. & $\begin{array}{c}\text { Frekuensi } \\
\text { Order }\end{array}$ & Jumlah & $\%$ \\
\hline 1. & 2 x Order & 37 & $43 \%$ \\
2. & $3 x$ Order & 16 & $19 \%$ \\
3. & $4 x$ Order & 9 & $10 \%$ \\
4. & $>5 x$ & 24 & $28 \%$
\end{tabular}

\begin{tabular}{ccc} 
Total & 86 & $100 \%$ \\
\hline Sumber : Data Primer yang diolah &
\end{tabular}

Berdasarkan table 4 dapat diketahui bahwa frekuensi order layanan GoFood pada aplikasi Gojek yang dilakukan oleh responden dalam waktu satu sampai tiga bulan terakhir adalah 2 kali order sebagai jawaban tertinggi sebanyak 37 orang atau $43 \%$. Hal ini menunjukkan bahwa responden cukup sering melakukan pemesanan melalui jasa layanan GoFood.

\section{Uji Validitas}

Berdasarkan hasil uji validitas diperoleh hasil bahwa semua pernyataan (32 item) yang digunakan untuk mengukur variabel-variabel digunkaan dalam

Doi : https://doi.org/10.52655/khg.v1i1.3 
Revised : June, 22, 2021

Available online : June, 23, 2021

penelitian ini mempunyai koefisien korelasi yang lebih besar dari $r$ tabel $=0.209$ (nilai $r$ tabel untuk $\mathrm{n}=86$ ), sehingga semua pernyataan tersebut adalah valid.

\section{Uji Reliabilitas}

Berdasarkan hasil uji reliabilitas menunjukkan bahwa ketiga variabel mempunyai koefisien alpha yang cukup baik, yaitu diantara 0,600 sampai 0,800 $(0.800<\mathrm{a}<0,600)$. Sehingga dapat dikatakan semua konsep pengukur masingmasing variabel dari kuisioner adalah reliable.

\section{Uji Asumsi Klasik}

\section{Uji Normalitas}

Berdasarkan hasil uji normalitas dengan P Plot diperoleh sebaran titik-titik relatif mendekati garis lurus atau garis diagonal, sehingga dapat dikatakan bahwa (data) residual berdistribusi normal.

\section{Uji Linieritas}

Berdasarkan hasil uji Linieritas diperoleh nilai uji variabel Persepsi Harga (X1) signifikansi (linearity) 0,000 variabel Citra Merek (X2) signifikansi (linearity) 0,000 dan variabel Kualitas Pelayanan (X3) signifikansi (linearity) 0,000, maka disimpulkan ketiga variabel mempunyai hubungan yang linear.

\section{Uji Multikolonieritas}

Berdasarkan Tabel diatas menunjukkan bahwa variabel bebas mempunyai nilai tolerance $>0.1$ dan nilai < 10. Yaitu Persepsi Harga 0.645, Citra Merek 0.572 dan Kualitas Pelayanan 0.467 > 0,1 sedangkan VIF Persepsi Harga 1.550, Citra Merek 1.747 dan Kualitas Pelayanan $1.980<10$ Jadi dapat disimpulkan bahwa tidak ada multikolinieritas antar variabel bebas.

\section{Uji Heteroskedastisitas}

Berdasarkan hasil grafik Scatterplot terlihat titik-titik yang menyebar secara acak, tidak membentuk suatu pola tertentu yang jelas, serta tersebar baik di atas maupun di bawah angka 0 (nol) pada sumbu $Y$, hal ini berarti tidak terjadi penyimpangan asumsi klasik heteroskedastisitas pada model regresi yang dibuat.

\section{Hasil Uji Hipotesis}

Tabel 5. Hasil Analisa Regresi Berganda

\begin{tabular}{lcccc}
\hline variabel & $\begin{array}{c}\text { Koefesien } \\
\text { Regresi }\end{array}$ & $\begin{array}{c}\mathbf{t} \\
\text { hitung }\end{array}$ & Probabilitas & Ket \\
\hline Persepsi & 0.232 & 6.113 & 0,000 & Diterima \\
Harga & & & & \\
Citra & 0.204 & 6.495 & 0,000 & Diterima \\
Merek & & & & \\
Kualitas & 0.489 & 8.503 & 0,000 & Diterima \\
Pelayanan & & & & \\
\hline Konstanta & 1.039 & & & \\
F Hitung & 30.356 & & & \\
$\mathrm{R}^{2}$ & 0.526 & & & \\
Adjusted & 0.509 & & & \\
$\mathrm{R}^{2}$ & & & & \\
\hline
\end{tabular}


Terdapat pengaruh positif dan signifikan dari variable persepsi harga terhadap minat beli ulang jasa GoFood di Kota Sorong. Hal ini terbukuti dengan nilai $\mathrm{t}$ hitung $>\mathrm{t}$ tabel $(6.113>1.989)$ dan taraf signifikan kurang dari $0,05(0,000<0,05)$ artinya apabila harga yang ditawarkan oleh GoFood sesuai dengan keinginan konsumen maka akan mendorong pengguna jasa layanan GoFood untuk terus melakukan pembelian secara terus menerus . Hasil dari penelitian ini sejalan dengan penelitian sebelumnya oleh Yuwan Soelistio (2016) yang menyatakan terdapat persepsi harga dapat mempengaruhi minat pembelian ulang.

Terdapat pengaruh positif dan signifikan dari citra merek terhadap minat beli ulang jasa GoFood di Kota Sorong. Hal ini terbukuti dengan nilai $\mathrm{t}$ hitung $>\mathrm{t}$ tabel (6.495 > 1.989) dan taraf signifikan kurang dari $0,05(0,000<0,05)$ artinya apabila konsumen memandang bahwa citra merek perusahaan Gojek dengan layanan GoFood baik maka akan meningkatkan minat konsumen untuk terus menggunakan GoFood. Hasil penelitian ini mendukung penelitian sebelumnya oleh Mendrika, n.d.) (2017) yang menyatakan bahwa citra merek dapat meningkatkan keinginan konsumen untuk melakukan pembelian ulang. pelayanan terhadap minat beli ulang Jasa GoFood di Kota Sorong. Hal ini terbukuti dengan nilai $\mathrm{t}$ hitung > t tabel $(8.503>$ 1.989) dan taraf signifikan kurang dari 0,05 $(0,000<0,05)$ artinya apabila kualitas pelayanan GoFood ditingkatkan maka akan mendorong pengguna jasa layananan GoFood untuk melakukan pembelian secara terus menerus. Hasil dari penelitian ini mendukung penelitian sebelumnya oleh Marieta (2017)) yang menyatakan bahwa kualitas pelayanan memiliki dampak yang signifikan terhadap minat beli ulang konsumen.

\section{KESIMPULAN}

Berdasarkan hasil penelitian dan pengujian data yang telah dilakukan, maka dapat disimpulkan bahwa terdapat pengaruh positif dan signifikan dari ketiga variable yaitu persepsi harga, citra merek dan kualitas pelayanan terhadap minat beli ulang jasa layanan GoFood. Hal ini menunjukkan apabila ketiga variable ini lebih ditingkatkan lagi maka akan mendorong konsumen untuk kembali menggunakan jasa layanan GoFood secara terus menerus. Adapun saran untuk penelitian selanjutnya agar mengembangkan variabel bebas yang belum diteliti dalam penelitian ini, 
Revised : June, 22, 2021

Available online : June, 23, 2021

kemudian penelitian ini juga dapat lebih

dikembangkan dengan menggunakan alat analisa lain. Bagi penyedia jasa layanan GoFood dalam hal ini adalah perusahaan Gojek agar dapat memperbaiki atau menambahkan fitur -fitur dalam aplikasi GoFood agar lebih memudahkan dan mempercepat konsumen dalam melakukan proses pemesanan.

\section{DAFTAR PUSTAKA}

AMILIA, S. (2017). Pengaruh Citra Merek, Harga, dan Kualitas Produk terhadap Keputusan Pembelian Handphone Merek Xiaomi di Kota Langsa. Jurnal Manajemen Dan Keuangan Unsam.

Bahar, A., \& Sjahruddin, H. (2017). Pengaruh Kualitas Produk Dan Kualitas Pelayanan Terhadap Kepuasan Konsumen Dan Minat Beli Ulang. 3, 14-34. https://doi.org/10.31227/osf.io/tc2fe

Hakim, L. N. (2021). Effect of Product Quality and Service Quality on Customer Loyalty with Customer Satisfaction as an Intervenning Variables (Case Study on the Tirta Jasa Lampung Selatan Regional Company (PDAM)). Economit Journal: Scientific Journal of Accountancy, Management and Finance, 1(1), 48-56. https://doi.org/10.33258/economit.v1i1.374

Lubis, A. S., \& Andayani, N. R. (2018). Pengaruh Kualitas Pelayanan (Service Quality) Terhadap Kepuasan Pelanggan Pt. Sucofindo Batam. Journal of Applied Business Administration, 1(2), 232-243. https://doi.org/10.30871/jaba.v1i2.619

Marieta, P. D. (2017). Pengaruh kualitas pelayanan terhadap minat beli ulang Studi kasus pada Legend Coffee Yogyakarta. In Repository Skripsi thesis, Sanata Dharma University (Vol. 6, Issue 1).
Mendrika, S. G. (2017). (n.d.). Pengaruh Brand Image terhadap minat beli ulang Oriflame studi kasus: mahasiswi Kampus 1 Universitas Sanata Dharma.

Samosir, C. B. H., \& Prayoga, A. B. (2015). Pengaruh Persepsi Harga dan Promosi terhadap Keputusan Pembelian Konsumen Produk Enervon-C. Jurnal Ilmiah Manajemen Dan Bisnis, 1(November), 1-13.

Soelistio, Y. (2016). Pengaruh Persepsi Harga, Promosi, Dan Kualitas Layanan Terhadap Minat Pembelian Jasa Paket Pos Indonesia.

Wijaya, N. \& W. (2019). Analisis Faktor-Faktor Yang Mempengaruhi Minat Beli Ulang Masyarakat Terhadap Produk Handphone. Journal of Chemical Information and Modeling, 53(9), 1689-1699 